\title{
Téoros
}

Revue de recherche en tourisme

\section{Managing and Marketing Tourist Destinations, Metin KOZAK et Seyhmus BALOGLU, New York, London : Routledge, 2011, 242 pages, ISBN 13:978-0-415-99171-1 (hbk) ISBN 13:978-0-203-84230-0 (elok)}

\section{François Bédard}

Volume 30, numéro 1, 2011

URI : https://id.erudit.org/iderudit/1012118ar

DOI : https://doi.org/10.7202/1012118ar

Aller au sommaire du numéro

Éditeur(s)

Université du Québec à Montréal

ISSN

0712-8657 (imprimé)

1923-2705 (numérique)

Découvrir la revue

Citer ce compte rendu

Bédard, F. (2011). Compte rendu de [Managing and Marketing Tourist Destinations, Metin KOZAK et Seyhmus BALOGLU, New York, London : Routledge, 2011, 242 pages, ISBN 13:978-0-415-99171-1 (hbk) ISBN 13:978-0-203-84230-0 (ebk)]. Téoros, 30(1), 148-148.

https://doi.org/10.7202/1012118ar d'utilisation que vous pouvez consulter en ligne. 


\section{POUR EN LIRE PLUS}

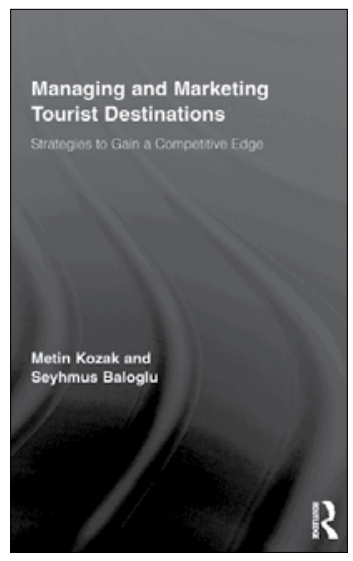

\section{Managing and Marketing Tourist Destinations}

Metin KOZAK et Seyhmus BALOGLU

New York, London : Routledge, 2011, 242 pages

ISBN 13:978-0-415-99171-1 (hbk)

ISBN 13:978-0-203-84230-0 (ebk)

L'ouvrage de Kozak et Baloglu traite des stratégies permettant aux destinations touristiques d'obtenir et de maintenir un avantage concurrentiel. Dans le contexte actuel où le nombre déjà fort imposant de destinations dans le monde ne cesse de croître, cet ouvrage s'avère particulièrement utile pour toutes les parties prenantes d'une destination à la recherche de l'excellence.

La première partie intitulée Destination Competitiveness traite des nombreux aspects reliés à la compétitivité d'une destination. Après une énumération des raisons démontrant l'importance de ce sujet, les auteurs présentent une revue exhaustive de la littérature sur le concept de la compétitivité des destinations. Par la suite, ils brossent un tableau des différents éléments qui sont déterminants pour qu'une destination soit concurrentielle. S'inspirant du modèle de Porter (1985) sur l'analyse de l'environnement concurrentiel d'une entreprise, Kozak et Baloglu proposent un cadre théorique comprenant les cinq éléments ayant une influence sur la compétitivité d'une destination; il s'agit de l'offre, de la demande, des intermédiaires dans la distribution, de l'émergence de nouvelles destinations et finalement de l'émergence de produits et services de substitution.

Sous le titre de Destination Management, les auteurs abordent en deuxième partie de l'ouvrage les questions relatives aux capacités internes des destinations et aux habiletés de gestion. Ils expliquent, à l'aide de modèles, comment l'élaboration et la mise en œuvre des stratégies pour une destination, ainsi que la pratique de la gestion de la qualité totale dans le contexte d'une destination et l'analyse comparative des destinations (benchmarking) peuvent contribuer à l'augmentation de parts de marché et à l'amélioration du niveau concurrentiel d'une destination à l'échelle internationale.

La troisième et dernière partie de l'ouvrage est consacrée au thème du Destination Marketing. Cette partie est subdivisée en trois sous-thèmes : les stratégies de marketing, la marque (branding) et le Web marketing. En ce qui a trait aux stratégies de marketing, Kozak et Baloglu rappellent les fondements et l'utilité des concepts de positionnement de la destination, de diversification du produit et de segmentation des marchés. Ils soulignent que, pour être visible sur le marché, toute destination doit se doter d'une marque distinctive, laquelle, en faisant ressortir sa personnalité propre, permet de la différencier de la multitude de destinations qui se battent pour attirer les touristes chez eux. Enfin, ils décrivent le passage graduel du marketing traditionnel au Web marketing observé chez les destinations touristiques tout en faisant ressortir comment les technologies sont devenues aujourd'hui des outils concurrentiels incontournables.

En ayant adopté une approche internationale, les auteurs ont sans doute cherché à joindre un large public. L'intérêt de cet ouvrage réside dans la grande diversité des principes, des modèles et des techniques présentés sur la gestion et le marketing des destinations, lesquels sont applicables dans des entreprises de petite ou grande taille (musées, hôtels, parcs nationaux, etc.) et dans des destinations de différentes échelles (ville, région, pays). La présentation, à la fin de chacun des neuf chapitres, d'une étude de cas rédigée par des universitaires contribue à enrichir le contenu de cet ouvrage et à en faire une référence utile à la fois pour les professionnels et les gens du milieu de l'enseignement et de la recherche.

François BÉDARD, Ph.D., Professeur, Département d'études urbaines et touristiques (ESG-UQAM) 